\title{
Identification of Shoot Traits Related to Drought Tolerance in Common Bean Seedlings
}

\author{
Gerardine Mukeshimana \\ Biosciences Eastern and Central Africa (BecA)-International Livestock Research Institute (ILRI) \\ Hub, P.O. Box 30709-00100, Nairobi, Kenya
}

Amy L. Lasley

PhytoGen Seed Co. LLC, 118 Kennedy Flat Road, Leland, MS 38756

Wayne H. Loescher'
Department of Horticulture, Michigan State University, 1066 Bogue Street, East Lansing MI 48824
James D. Kelly
Department of Plant, Soil, and Microbial Sciences, Michigan State University, 1066 Bogue Street,
East Lansing MI 48824

AdDitional Index words. gene pools, Phaseolus vulgaris, races, slow wilting, stomatal conductance

\begin{abstract}
Drought is an important abiotic stress that limits common bean (Phaseolus vulgaris) productivity. The objective of this study was to determine shoot traits that are associated with drought tolerance in common bean seedlings. Ten common bean genotypes consisting mainly of cultivars and breeding lines from the Mesoamerican race of the Middle American gene pool were first evaluated in the greenhouse. Genotypes were grown in a shallow soil profile to limit root growth and assess shoot phenotypes under stress. Water stress was imposed by withholding watering for 24 days after planting. Traits evaluated included wilting, unifoliate senescence, stem greenness, and recovery from drought. Biomass and number of pods/plant produced after drought recovery were evaluated to quantify the effect of early drought stress on bean growth and reproduction. A second group of 94 common bean genotypes from the Bean Coordinated Agricultural Project (BeanCAP) were evaluated using the same protocol to determine the genetic variability for the same traits in a wider range of genotypes. In general, genotypes known to possess drought avoidance in the field conferred by deep rooting traits performed poorly in these conditions suggesting that the assay could be used to identify seedling shoot traits that contribute to drought tolerance. Genotypes from race Mesoamerica showed the greatest range in wilting. Genotypes that showed a slow rate of wilting maintained a green stem and had a higher recovery rate after watering. Importantly, these genotypes demonstrated a smaller reduction in biomass and pod number under stress compared with non-stress treatments. A few genotypes recovered completely despite expressing severe wilting, whereas the majority of genotypes with high wilting rates did not recover. Among the BeanCAP materials, genotypes bred in the rainfed midwestern United States showed overall better recovery than those bred under the irrigated production system used in the western United States. Because recovery from drought is a prerequisite to plant regrowth, biomass, and pod production after drought stress, factors that contribute to recovery were studied. Stem greenness was highly positively correlated to the recovery, whereas wilting was negatively correlated to the recovery. In a regression analysis, stem greenness and slow wilting were found to be important contributors to the variability of recovery. In addition, photosynthetic rate and stomatal conductance $\left(g_{\mathrm{S}}\right)$ explained variation in wilting and stem greenness. These results suggest that wilting and stem greenness might be useful traits to screen for drought tolerance in seedlings of common bean.
\end{abstract}

Common bean is an important food legume. Globally, $60 \%$ of common bean production is located in drought-prone areas where irrigation is not available or farmers cannot afford the cost associated with irrigation (Beebe, 2012). In addition, competition with major crops continues to push common beans into marginal lands that exhibit increased risk of drought stress. Common bean crops are subject to erratic rainfall at different growth stages resulting in substantial reduction in biomass and

Received for publication 11 Sept. 2013. Accepted for publication 5 Mar. 2014 This project was partially supported by the Agriculture and Food Research Initiative competitive grant \# 2010-85117-20570 of the USDA National Institute of Food and Agriculture and by funds from the U.S. Agency for International Development (USAID) through the Dry Grain Pulses Collaborative Research Support Program (Cooperative Agreement EDH-A-00-07-00005-00).

The content is solely the responsibility of the author(s) and does not necessarily represent the official views of USAID.

${ }^{1}$ Corresponding author. E-mail: loescher@msu.edu. seed yield. Intermittent drought stress during the seedling stage affects overall plant growth, whereas terminal drought significantly reduces bean seed yield and seed size during the critical reproductive period (Singh, 2007). Seed quality is also negatively affected under prolonged periods of terminal drought. Because the incidence and duration of drought episodes are expected to increase with climate change, approaches to breeding common bean for drought tolerance were recently summarized by Beebe et al. (2013). Screening of breeding materials in controlled greenhouse and growth chambers could improve efficiency in breeding for drought tolerance. Importantly, screening for drought tolerance at the seedling stage permits efficient screening of large numbers of materials in reasonable time and space. Therefore, breeders need to determine which seedling stage traits could be used to identify drought-tolerant lines early in the selection processes. Drought episodes occurring early in plant development can also have a major negative impact 
on crop yield. The extent of recovery affects growth and development of sink size as well as source supply when plant growth resumes after vegetative-stage drought. Slow or incomplete photosynthetic recovery can negatively impact plant productivity (Chaves et al., 2011). For instance, the retention of green leaf area and the number of leaves surviving at the end of drought stress have been shown to affect the ability of rice (Oryza sativa) seedlings to recover and tiller (Kamoshita et al., 2008; Mitchell et al., 1998). In soybean (Glycine max), drought at the seedling stages reduces the number of nodes, internode length, overall biomass, and the number of flowers produced with an associated reduction of yield and yield components (Desclaux et al., 2000). In sunflower (Helianthus annuus), drought during the vegetative phase reduces main stem height, stem diameter, number of nodes or leaves, and leaf area affecting the final yield (Rauf, 2008). Finally, drought at the seedling stage often delays developmental events because of the inhibition of growth during the water deficit period (Blum, 1996) and this can cause severe yield loss if the recovery happens late in the season.

Plant shoots and roots act independently or synergistically to enable plants to cope with drought stress. For instance, drought tolerance in cowpea (Vigna unguiculata) depends on the shoot when root volume is constrained and both root and shoot factors mediated tolerance when root volume is unconstrained (Watanabe et al., 1997). Common beans have four distinct growth habits that are classified into four shoot types I to IV, each with unique properties (Singh, 1982). These growth habits can be determinate or indeterminate and differ in spatial layout of branching and climbing ability (Singh, 1982). When different common bean shoot genotypes were grafted onto different root genotypes and their performance tested under drought stress, the effect of shoot genotype was small in comparison with root genotype, but the shoot genotype still played an important role in overall drought tolerance (White and Castillo, 1989). Combining root traits with shoot-based drought tolerance mechanisms in single genotypes should enhance the development of drought-resistant beans.

Various shoot traits have been investigated in common bean at the seedling stage (Beebe et al., 2013). These include physiological processes such as photosynthetic efficiency, total chlorophyll content, $g_{\mathrm{S}}$, transpiration rate, leaf temperature, and leaf water potential (Castrillo et al., 2001; Dias and Brüggemann, 2010; Lizana et al., 2006; Ninou et al., 2013; Wentworth et al., 2006). However, these traits showed variable results in terms of association to drought tolerance and are not easily amenable to large-scale screening of breeding lines generated in most breeding programs. Fast and cost-effective methods to screen common bean seedlings are still needed. Various shoot criteria are used to evaluate drought tolerance at the seedling stage in other crops. For example, in wheat (Triticum aestivum), sunflower, and cotton (Gossypium hirsutum), seedling recovery after stress is used as a criterion to assess drought tolerance (Longenberger et al., 2006; Rauf, 2008; Tomar and Kumar, 2004). Tolerance to seedling leaf death and recovery has also been used as a screening trait in rice (DeDatta et al., 1988; Mitchell et al., 1998). In legumes, different shoots traits are used to select drought-tolerant genotypes. For instance, maintenance of green stem was shown to be an important criterion for seedling stage drought tolerance in cowpea (Muchero et al., 2008), whereas a slow wilting trait is associated with drought tolerance in soybean (Sadok et al., 2012). In cowpea, the "wooden box" seedling screening method was developed for phenotyping cowpea for drought tolerance
(Singh et al., 1999). This method provides the advantage of limiting root growth to assess the shoot drought tolerance mechanisms. This technique has been adapted to screen various other crops including cotton, wheat, and watermelon (Citrullus lanatus) (Longenberger et al., 2006; Tomar and Kumar, 2004; Zhang et al., 2011). However, one of the limitations of the wooden box method is that seedlings grown in the same box will compete with each other for limited moisture present. Evaluation of seedlings on a single-plant basis in small pots where root expansion is limited would provide the benefits of the wooden box method while eliminating competition among different seedlings.

The primary objective of this study was to develop a greenhouse seedling screening test for shoot drought tolerance. This involved 1) evaluating the response of common bean seedlings to early drought stress when grown under root-limiting conditions; 2) determining which shoot traits would be most suitable to screen for drought tolerance under these conditions; and 3 ) determining the relative drought response of a larger group of common bean genotypes previously evaluated for drought avoidance in the field.

\section{Materials and Methods}

Plant material. In the first set of experiments, 10 common bean genotypes were used based on previous information of their response to drought in the field. Nine genotypes from the Mesoamerican race of the Middle American gene pool (Singh et al., 1991) were chosen to maintain genetic similarity among genotypes so that drought response can be monitored easier and not be confounded by differences in phenology and growth habit. These included small-seeded black bean cultivars and breeding lines 'Blackhawk', 'Jaguar', 'Phantom', 'Zorro', L88-63, and B98311, and red-seeded lines, TARS-SR05 and RAB 651. One cultivar, Concepción, from the Andean gene pool was used in the earlier experiments and was later replaced by the otebo cultivar, Fuji, that was previously shown to be very susceptible to drought under field conditions.

'Zorro' is a high-yielding, widely grown black bean cultivar that has shown good field tolerance to drought tracing back to its B98311 drought-tolerant grandparent (Kelly et al., 2009a). Black bean cultivars Jaguar (Kelly et al., 2001), Phantom (Kelly et al., 2000), and Blackhawk (Ghaderi et al., 1990) are similar to 'Zorro' in agronomic traits and exhibit the same upright type II indeterminate short vine growth habit (Singh, 1982) but are not recognized as being drought-tolerant. Michigan State University (MSU) black bean breeding line B98311 is recognized to possess high levels of drought tolerance conferred by a deep vigorous taproot (Frahm et al., 2004). MSU black bean breeding line L88-63 was developed from the cross of B98311 $\times$ TLP19 and was selected as a drought-resistant line in field evaluations in Honduras, Mexico, and Michigan (Frahm et al., 2004). The TLP19 parent from the International Center for Tropical Agriculture (CIAT) breeding program is recognized as a shallow rooting genotype selected to more efficiently uptake phosphorus (Beebe et al., 2013). TARS-SR05 is a small red breeding line that combines multiple root rot disease resistance with tolerance to low soil fertility and is recognized as being stress-tolerant (Smith et al., 2007). RAB 651 is a small, red-seeded, indeterminate Mesoamerican race breeding line from CIAT that had not previously been selected for drought tolerance during its development but was recognized to express a high level of drought 
tolerance when evaluated as an advanced line. 'Concepción' is a large-seeded red-purple mottled cultivar with determinate type I growth habit (Singh, 1982) that was the droughtsusceptible parent in a mapping population. It was dropped from the experiment as a result of a lack of adaptation and replaced by the 'Fuji' otebo cultivar. 'Fuji' is a specialty white bean that possesses a determinate type I growth habit and is recognized as being sensitive to drought stress (Kelly et al., 2009b).

In the second set of experiments, 96 dry bean genotypes from the Bean Coordinated Agricultural Project (BeanCAP, 2011) were selected to gain greater insight in drought tolerance response in common bean. The genotypes were previously selected by a group of breeders in the United States and Puerto Rico for more extensive testing as part of the BeanCAP research projects being conducted in different production areas. The selections represent old and contemporary dry bean cultivars that differ in their response to drought in the field (BeanCAP, 2011). The study was limited to common bean genotypes from the Middle American gene pool and the experiment included 15 black, eight navy, two tan, and one carioca genotypes from race Mesoamerica; 16 great northern (GN) and 34 pinto genotypes from race Durango; and 10 pink and eight small red from race Jalisco (Singh et al., 1991). All race Mesoamerica genotypes and contemporary race Durango and Jalisco genotypes possess the type II growth habit, whereas the older race Durango and Jalisco genotypes possess the prostrate type III indeterminate growth habit (Singh, 1982). Information on agronomic characteristics and release date of the older cultivars was previously published by Sutton and Coyne (2002). 'Jaguar', B98311, and 'Fuji' served as checks based on their reaction to drought stress in the previous study.

Greenhouse experiments. Experiments were modified from the greenhouse protocol used to study drought reaction in cowpea (Muchero et al., 2008). Four experiments were conducted in the greenhouse during Winter and Spring 2009 and 2010 on the first group of 10 genotypes. Summer seasons were avoided to limit confounding factors from excessive heat in the greenhouse and the middle bench was used to avoid microclimates associated with ventilation and cooling systems along the greenhouse perimeter. Greenhouse temperatures were kept at 22 to $25^{\circ} \mathrm{C}$ and a 16 -h photoperiod.

Each experiment was conducted in a completely randomized design with five replications in $1200-\mathrm{cm}^{3}$ plastic pots. In addition, an equal number of replicates was planted and used as a control maintained under irrigation. In the first two experiments, pots were filled with $200 \mathrm{~g}$ of a mixture $(3: 1 \mathrm{v} / \mathrm{v})$ of Baccto potting mix (Michigan Peat Co., Houston, TX) and coarse perlite. In the last two experiments, $200 \mathrm{~g}$ of perlite (Suremix; Michigan Grower Products, Galesburg, MI) were used as the potting medium. Small pots and the limited amount of soil were used to limit root growth so that drought-tolerant shoot phenotypes could be assessed. All pots were watered to field capacity and excess water allowed to drain for $4 \mathrm{~h}$ before planting. Each genotype was planted with three seeds visually selected for size and quality. A second and last water application was made after planting in drought-stressed pots, whereas the controls continued to be irrigated to field capacity on 2-d intervals. Seedlings were thinned to one plant at $7 \mathrm{~d}$ post-planting. Drought stress was imposed very early to avoid confounding factors associated with plant size and vigor specific to each genotype. In drought stress experiments, individual plants were scored for wilting, unifoliate senescence, and maintenance of stem greenness. Wilting was scored at 18, 21, and $24 \mathrm{~d}$ after planting. At $24 \mathrm{~d}$, watering was resumed at 2-d intervals for $14 \mathrm{~d}$ when genotypes were scored for the recovery. All the pots in stress and nonstress conditions were fertilized at $25 \mathrm{~d}$ after planting with $20 \mathrm{~mL}$ of $20 \mathrm{~N}-8.8 \mathrm{P}-16.6 \mathrm{~K}$ water-soluble fertilizer (Peters Professional 20-20-20; Scotts, Marysville, OH). All experiments continued to be watered to field capacity every $2 \mathrm{~d}$ until midpod filling where the number of pods produced/plant was counted and dry biomass determined. Additional measurements of $g_{\mathrm{S}}$ and photosynthetic rates were measured at $18 \mathrm{~d}$ after planting in the third experiment. Stomatal conductance and photosynthetic rates were measured at ambient light intensities and a $\mathrm{CO}_{2}$ reference concentration of $380 \mu \mathrm{mol} \cdot \mathrm{mol}^{-1}$ using a portable photosynthesis system (LI-6400XT; LI-COR Biosciences, Lincoln, NE).

GrowTH CHAMbER EXPERIMENTS. The second set of experiments with the 96 genotypes was conducted in nine random groups as a result of the limited space in the growth chamber and the large number of genotypes. Each group consisted of 10 genotypes plus three checks ('Jaguar', 'Fuji', and B98311) except for the final group, which had only six genotypes and checks. Five replicates of each genotype were evaluated within each of the nine groups. Five blocks were created and genotypes were randomly placed in each of the five blocks. These experiments were conducted during the winter from Aug. 2011 through Apr. 2012. Growing conditions in the growth chamber were set at $26{ }^{\circ} \mathrm{C}, 16$-h day with 8-h night. Each genotype was planted in $1200-\mathrm{cm}^{3}$ pots in $150 \mathrm{~g}$ of potting soil at a seeding rate of three seeds per pot. Pots were watered to field capacity and allowed to drain at planting. After germination, plants were thinned to one seedling per pot. Drought stress was induced by discontinuing watering until data were collected $\approx 2$ weeks after planting. No additional water was provided between planting and data collection on wilting, greenness, and unifoliate senescence. After the collection of these data at $\approx 21 \mathrm{~d}$, watering was resumed every other day for 2 weeks. At the end of the 2 -week recovery period, genotypes were rated for recovery.

VARIABLES SCORING. Wilting was scored on a scale of 0 to 5 with 0 being no sign of wilting and 5 being completely wilted. Unifoliate senescing was assessed as the number of completely senescing unifoliates per pot taken when the most rapidly senescing genotypes had all the unifoliates dried. Stem greenness was scored on a scale of 0 to 5 with 0 being completely yellow and 5 being completely green. Recovery was rated on a scale of 0 to 1 (a 0 score was given to the genotype that did not recover, 0.5 if the recovery occurred at the basal node, and 1 if the recovery was from the top meristem).

Statistical ANALyses. All variables were analyzed using SAS (Version 9.3; SAS Institute, Cary, NC). Wilting was analyzed as repeated measurements using the generalized linear mixed model (GLIMMIX) procedure. Unifoliate senescence and recovery were analyzed as generalized linear models using the probit link function in the GLIMMIX procedure (Littell et al., 2006). Stem greenness, recovery number of pods, recovery fresh and dry biomass, $g_{\mathrm{S}}$, and photosynthetic rates were analyzed as mixed models using the MIXED procedure. Mean comparisons were performed using the least significant difference test with a significance level at $\alpha=0.05$. Phenotypic correlation and regression analyses were performed with PROC CORR and PROC REG. 
Table 1 . Mean scores for wilting at 18, 21, and $24 \mathrm{~d}$ after planting, unifoliate senescence, stem greenness, and recovery of 10 common bean genotypes evaluated under drought stress at the seedling stage. ${ }^{\mathrm{z}}$

\begin{tabular}{|c|c|c|c|c|c|c|}
\hline \multirow[b]{2}{*}{ Genotype } & \multicolumn{3}{|c|}{ Wilting $(0 \text { to } 5 \text { scale })^{\mathrm{y}}$} & \multirow{2}{*}{$\begin{array}{l}\text { Unifoliate senescence } \\
\qquad(0 \text { to } 2 \text { scale })^{\mathrm{x}}\end{array}$} & \multirow{2}{*}{$\begin{array}{l}\text { Stem greenness } \\
(0 \text { to } 5 \text { scale })^{\mathrm{w}}\end{array}$} & \multirow{2}{*}{$\begin{array}{c}\text { Recovery } \\
(0 \text { to } 1 \text { scale })^{v}\end{array}$} \\
\hline & $18 \mathrm{~d}$ & $21 \mathrm{~d}$ & $24 \mathrm{~d}$ & & & \\
\hline B98311 & $1.33 \mathrm{a}^{\mathrm{u}}$ & $3.10 \mathrm{a}$ & $4.39 \mathrm{a}$ & $0.87 \mathrm{a}$ & $2.06 \mathrm{~b}$ & $0.60 \mathrm{~b}$ \\
\hline Blackhawk & $1.05 \mathrm{a}$ & $2.55 \mathrm{a}$ & $4.20 \mathrm{a}$ & $0.84 \mathrm{a}$ & $2.55 \mathrm{~b}$ & $0.65 \mathrm{~b}$ \\
\hline Fuji & $0.89 \mathrm{ab}$ & $2.49 \mathrm{a}$ & $4.19 \mathrm{a}$ & $0.73 \mathrm{ab}$ & $3.50 \mathrm{a}$ & $0.48 \mathrm{~b}$ \\
\hline Jaguar & $0.50 \mathrm{~b}$ & $0.60 \mathrm{~b}$ & $2.65 \mathrm{~b}$ & $0.42 \mathrm{~b}$ & $3.80 \mathrm{a}$ & $0.97 \mathrm{a}$ \\
\hline L88-63 & $1.40 \mathrm{a}$ & $2.75 \mathrm{a}$ & $4.30 \mathrm{a}$ & $0.96 \mathrm{a}$ & $2.40 \mathrm{~b}$ & $0.60 \mathrm{~b}$ \\
\hline RAB651 & $0.70 \mathrm{ab}$ & $2.35 \mathrm{ab}$ & $4.25 \mathrm{a}$ & $0.87 \mathrm{a}$ & $2.50 \mathrm{~b}$ & $0.68 \mathrm{~b}$ \\
\hline TARS-SR05 & $1.25 \mathrm{a}$ & $2.25 \mathrm{ab}$ & $3.75 \mathrm{ab}$ & $0.76 \mathrm{ab}$ & $3.90 \mathrm{a}$ & $0.95 \mathrm{a}$ \\
\hline Zorro & $0.86 \mathrm{ab}$ & $1.97 \mathrm{~b}$ & $4.25 \mathrm{a}$ & $0.73 \mathrm{ab}$ & $2.70 \mathrm{~b}$ & $0.74 \mathrm{~b}$ \\
\hline
\end{tabular}

${ }^{\mathrm{z}}$ Each point represents an average of four experiments, each with five plants for each genotype.

${ }^{y}$ Wilting was scored on a scale of 0 to 5 with 0 being no sign of wilting and 5 being completely wilted.

${ }^{\mathrm{x}}$ Unifoliate senescence was recorded as the number of senesced leaves (zero to two) when the most rapidly senescing genotype had dried unifoliates.

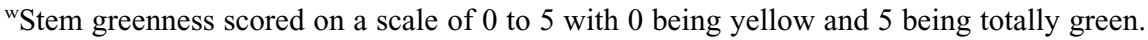

${ }^{v}$ Recovery scored on a scale of 0 to 1 with 0 being no recovery, 0.5 when the recovery occurred from the basal meristem, and 1 when recovery occurred from the apical meristem.

"Means with the same letter are not significantly different.

\section{Results}

WiLTING. Wilting increased over time during the stress period and average wilting scores were $1.05,2.21$, and 4.0 , respectively, at Days 18, 21, and 24 after planting (Table 1). Phenotypic correlation coefficients among the measurement times were high between adjacent measurement times. Specifically, the correlation coefficients were $0.73,0.70$, and 0.87 , respectively, between 18 and 21, 18 and 24, and 21 and $24 \mathrm{~d}$. Significant differences in wilting existed among genotypes $(P \leq 0.0016)$ and measurement times $(P \leq 0.0001)$. There were also interactions between genotype and measurement times $(P \leq 0.03)$. Small-seeded genotypes 'Jaguar', 'Phantom', RAB651, 'Zorro', and 'Fuji' did not show any significant wilting at Day 18 . However, all the genotypes wilted rapidly after Day 18 except 'Jaguar', which had a significantly lower wilting score than the other genotypes. RAB651, 'Zorro', and 'Fuji' had a low wilting score at Day 18, but the wilting rate from Days 21 to 24 was so rapid that no differences were observed with the faster wilting genotypes at Day 24 (data not shown). Wilting showed a significant positive correlation with unifoliate senescence, whereas it was negatively correlated with stem greenness, recovery, recovery number of pods, recovery fresh, and dry biomass (Table 2).

UNIFOLIATE SENESCENCE. There was a significant difference $(P \leq 0.015)$ for unifoliate senescence between genotypes. 'Jaguar' and 'Phantom' had lower average score for unifoliate senescence than the rest of genotypes, whereas L88-63, B98311, and RAB651 had the highest unifoliate senescence scores (Table 1). Unifoliate senescence was negatively correlated to all variables except wilting.

STEM GREENNESS. Significant differences $(P \leq 0.0001)$ for stem greenness were observed between genotypes. Genotypes TARS-SR05, 'Jaguar', 'Fuji', and 'Phantom' had high scores for stem greenness, whereas B98311, RAB651, and L88-63 had the lowest scores (Table 1). The stem greenness score of B98311 did not differ significantly from the score of 'Blackhawk', L88-63, RAB651, and 'Zorro'. Stem greenness was negatively correlated to wilting and unifoliate senescence but was positively correlated with recovery, pod number, fresh biomass, and dry biomass (Table 2).

Recovery from Drought. Significant differences $(P \leq$ $0.015)$ for recovery were observed among genotypes. Genotypes were classified into two groups (Table 1). The first group comprised genotypes 'Jaguar', TARS-SR05, and 'Phantom' with recovery rates of $0.97,0.95$, and 0.82 , respectively. The rest of the genotypes were grouped into the second category with low recovery rates. Recovery was negatively correlated to wilting and unifoliate senescence, whereas it was positively correlated to stem greenness, pod number, and biomass (Table 2). Because recovery from drought stress is important for subsequent plant growth and reproduction, regression analysis of recovery on wilting, unifoliate senescence, and stem greenness

Table 2. Spearman correlation coefficients among wilting, unifoliate senescence, stem greenness, recovery, pod number, and dry biomass for 10 common bean genotypes evaluated in the greenhouse under drought stress at the seedling stage. ${ }^{\mathrm{z}}$

\begin{tabular}{lcccc}
\hline & Wilting & Unifoliate senescence & Stem greenness & Recovery \\
\hline Unifoliate senescence & $0.62^{* * *}$ & & & \\
Stem greenness & $-0.68^{* * *}$ & $-0.52^{* * *}$ & $0.65^{* * *}$ & \\
Recovery & $-0.66^{* * *}$ & $-0.42^{* * *}$ & $0.54^{* * *}$ & $0.72^{* * *}$ \\
Pod number & $-0.63^{* * *}$ & $-0.44^{* * *}$ & $0.57^{* * *}$ & $0.79^{* * *}$ \\
Dry biomass & $-0.72^{* * *}$ & $-0.57^{* * *}$ & $0.83^{* * *}$ \\
\hline
\end{tabular}

${ }^{\mathrm{z}}$ Seedlings were grown in a shallow soil profile in small pots.

*** Significant at $P \leq 0.0001$. 
Table 3. Mean values for number of pods, dry biomass along with percent reductions for 10 common bean genotypes evaluated in the greenhouse under drought stress at the seedling stage. ${ }^{z}$

\begin{tabular}{|c|c|c|c|c|c|c|}
\hline \multirow[b]{2}{*}{ Genotype } & \multicolumn{3}{|c|}{ Pods (no.) } & \multicolumn{3}{|c|}{ Dry biomass (g) } \\
\hline & Non-stress & Stress & Reduction (\%) & Non-stress & Stress & Reduction (\%) \\
\hline B98311 & 7.73 & 2.80 & 64 & 9.68 & 2.14 & 78 \\
\hline Blackhawk & 7.53 & 3.66 & 51 & 11.34 & 5.44 & 52 \\
\hline Fuji & 8.85 & 0.05 & 99 & 9.40 & 1.18 & 87 \\
\hline Jaguar & 8.73 & 6.66 & 24 & 10.39 & 7.84 & 25 \\
\hline L88-63 & 6.87 & 3.20 & 53 & 8.93 & 2.91 & 67 \\
\hline RAB651 & 6.93 & 2.06 & 70 & 9.66 & 2.49 & 74 \\
\hline TARS-SR05 & 9.00 & 5.10 & 43 & 9.34 & 7.63 & 18 \\
\hline Zorro & 6.20 & 3.20 & 49 & 9.94 & 3.20 & 68 \\
\hline
\end{tabular}

${ }^{\mathrm{z}}$ Each point represents an average of four experiments, each with five plants for each genotype. Drought stress consisted of an initial watering for seedling establishment followed by withholding water for $24 \mathrm{~d}$ and then re-watering at 2-d intervals until final evaluations and harvest.

was used to predict variables that are likely to influence seedling recovery. As results, only stem greenness and wilting fitted in the model that explained $48 \%$ of variation in recovery. Stem greenness alone accounted for $43 \%$ of the variation in recovery.

Number OF PODs. The analysis of variance for pod number showed significant differences between stress and non-stressed treatments $(P \leq 0.0001)$ and among genotypes $(P \leq 0.0001)$. Water treatment $\times$ genotype interaction was not significant. The stressed treatment had an average of 3.3 pods, whereas the non-stress treatment had an average 7.3 pods. Drought stress significantly reduced the number of pods for all genotypes. Percentage pod number reduction was the highest in 'Fuji' (99\%), whereas it was lowest for 'Jaguar' (24\%) (Tables 3 and 4). 'Jaguar' and 'Phantom' did not show significant losses in pod number as a result of drought effects.

Biomass. Significant differences $(P \leq 0.0001)$ were observed for plant biomass between stress and non-stress treatments. The average dry biomass in stressed treatments was $4.2 \mathrm{~g}$, whereas

Table 4. Analysis of variance for number of pods, dry biomass, stomatal conductance, and photosynthesis of common beans evaluated in the greenhouse under ambient light conditions and drought stress and non-stress treatments at the seedling stage.

\begin{tabular}{|c|c|c|c|c|}
\hline & $\mathrm{df}$ & Mean square & $\mathrm{F}$ value & $P$ value \\
\hline Source & \multicolumn{4}{|c|}{ Number of pods } \\
\hline Genotype & 9 & 68.02 & 7.29 & $\leq 0.0001$ \\
\hline Water treatment & 1 & 945.75 & 101.41 & $\leq 0.0001$ \\
\hline \multirow[t]{2}{*}{ Water treatment $\times$ genotype } & 9 & 14.78 & 1.59 & 0.1205 \\
\hline & \multicolumn{4}{|c|}{ Dry biomass } \\
\hline Genotype & 9 & 28.15 & 3.21 & 0.0008 \\
\hline Water treatment & 1 & 1454.70 & 67.21 & $\leq 0.0001$ \\
\hline \multirow[t]{2}{*}{ Water treatment $\times$ genotype } & 9 & 24.72 & 3.64 & 0.0009 \\
\hline & \multicolumn{4}{|c|}{ Stomatal conductance } \\
\hline Genotype $^{z}$ & 8 & 0.005 & 2.17 & 0.0550 \\
\hline Water treatment & 1 & 0.532 & 238.89 & $\leq 0.0001$ \\
\hline \multirow[t]{2}{*}{ Water treatment $\times$ genotype } & 8 & 0.005 & 2.21 & 0.0511 \\
\hline & \multicolumn{4}{|c|}{ Photosynthesis } \\
\hline Genotype $^{\mathrm{z}}$ & 8 & 6.174 & 1.36 & 0.2492 \\
\hline Water treatment & 1 & 931.6 & 205.11 & $\leq 0.0001$ \\
\hline Water treatment $\times$ genotype & 8 & 5.824 & 1.28 & 0.2852 \\
\hline
\end{tabular}

${ }^{\mathrm{z}}$ Stomatal conductance and photosynthesis were measured on only nine genotypes from the Middle American gene pool ('Concepción' was no longer in use). the average biomass was $10.2 \mathrm{~g}$ in the non-stress treatment. In addition, significant differences were observed for genotype $(P \leq 0.0008)$ and genotype $\times$ water treatment interactions $(P \leq 0.0009)$. Under non-stress conditions, all genotypes had equivalent amounts of biomass. However, under stress conditions, genotypes 'Jaguar', 'Phantom', and TARS-SR05 (18\% to $36 \%$ ) had lower reductions of dry biomass than other genotypes (68\% to $87 \%$ ) (Tables 3 and 4$)$.

Рнотosynthesis. Photosynthetic rates were evaluated for Expt. 3 at Day 18. At this time, there were significant differences between water treatments $(P \leq 0.0001)$. However, there was no significant difference among genotypes within each water treatment or genotype $\times$ water treatment interactions. At ambient light levels in the greenhouse, in the stress treatment, the average photosynthetic rate was $3.2 \mu \mathrm{mol} \cdot \mathrm{m}^{-2} \cdot \mathrm{s}^{-1}$, whereas the rate was $11.5 \mu \mathrm{mol} \cdot \mathrm{m}^{-2} \cdot \mathrm{s}^{-1}$ in the non-stress treatment. Although no significant differences among genotypes were observed, RAB651 and TARS-SR05 appeared to have lower photosynthetic rates under drought stress. Certain genotypes such as 'Jaguar', TARS-SR05, and 'Phantom' did not have high photosynthetic rates under non-stress, but they were able to maintain relatively higher photosynthetic rates under drought conditions (Tables 4 and 5).

Stomatal Conductance. Stomatal conductance was evaluated at the same time as photosynthetic activity. Photosynthesis and $g_{\mathrm{S}}$ were highly correlated to each other $\left[r=0.98^{* *}\right.$ and $0.91^{* *}(P \leq 0.01)$ for stress and non-stress, respectively]. Although the analysis of variance did not show any difference between genotypes or a genotype $\times$ water treatment interaction, there was a significant difference between stress and non-stress treatments $(P \leq 0.003)$. The average $g_{\mathrm{S}}$ was $0.0205 \mathrm{mmol} \cdot \mathrm{m}^{-2} \cdot \mathrm{s}^{-1}$ in stress treatments, whereas it was 10 -fold greater $\left(0.225 \mathrm{mmol} \cdot \mathrm{m}^{-2} \cdot \mathrm{s}^{-1}\right)$ in non-stress treatments. Genotypes RAB651 and B98311 had lower $g_{\mathrm{S}}$ in stress treatments. However, under non-stress, genotypes B98311, 'Fuji', and 'Zorro' had relatively high $g_{\mathrm{S}}$ compared with the other genotypes (Tables 4 and 5).

GAS EXCHANGE IN RELATION TO WILTING, STEM GREENNESS, AND RECOVERY. When $g_{\mathrm{S}}$ and photosynthetic rate were regressed on wilting (Fig. 1), stem greenness (Fig. 2), and recovery (Fig. 3), there was a strong negative relationship between wilting and photosynthesis and $g_{\mathrm{S}}\left(r=-0.81^{* *}\right)$. Variation in stem greenness variation was positively associated with photosynthetic rate and $g_{\mathrm{S}}\left(r=0.94^{* *}\right.$ and $0.91^{* *}$, respectively $)$. Similarly, recovery was 
Table 5. Mean values for photosynthetic rates and stomatal conductance $\left(g_{\mathrm{s}}\right)$ for nine common bean genotypes evaluated in the greenhouse under ambient light conditions and drought stress and non-stress treatments at the seedling stage. ${ }^{\mathrm{z}}$

\begin{tabular}{lccccc}
\hline & \multicolumn{2}{c}{$\begin{array}{c}\text { Photosynthetic rate } \\
\left(\mu \mathrm{mol} \cdot \mathrm{m}^{-2} \cdot \mathrm{s}^{-1}\right)\end{array}$} & & \multicolumn{2}{c}{$\begin{array}{c}g_{\mathrm{S}} \\
\left(\mathrm{mmol} \cdot \mathrm{m}^{-2} \cdot \mathrm{s}^{-1}\right)\end{array}$} \\
\cline { 2 - 3 } \cline { 5 - 6 } Genotype & Stress & Non-stress & & Stress & Non-stress \\
\hline B98311 & 2.20 & 13.42 & & 0.01 & 0.27 \\
Blackhawk & 3.26 & 13.22 & & 0.02 & 0.23 \\
Fuji & 3.91 & 13.32 & & 0.02 & 0.29 \\
Jaguar & 4.27 & 10.88 & & 0.03 & 0.20 \\
L88-63 & 2.66 & 9.96 & & 0.02 & 0.19 \\
Phantom & 3.59 & 11.01 & & 0.02 & 0.24 \\
RAB651 & 1.94 & 8.79 & & 0.01 & 0.15 \\
TARS-SR05 & 4.04 & 9.63 & & 0.03 & 0.13 \\
Zorro & 2.69 & 13.10 & & 0.02 & 0.27 \\
\hline
\end{tabular}

${ }^{\mathrm{z}}$ Each point represents an average of four experiments, each with five plants for each genotype.

positively correlated with photosynthesis and $g_{\mathrm{S}}\left[r=0.73^{*}\right.$ and $0.75^{*}(P \leq 0.05)$, respectively].

BeanCAP SCReEning. Partial data on wilting, unifoliate senescence, stem greenness, and recovery of the 96 BeanCAP entries are presented in Tables $6-8$ separately by race because initial differences in seed size may influence the rating taken in the seedling stage and invalidate comparisons among genotypes contrasting in seed size. Wilting scores of 96 entries ranged from a low of 1.6 for 'Eclipse' black bean to values as high as 4.4 for 'Domino black', 'Matterhorn GN', and 'Common Red Mexican' genotypes. The greatest range in wilting scores appeared in the Mesoamerican race with both extremes observed in black beans (Table 6). The 'Jaguar' control had a higher wilting value than expected based on earlier experiments, but the lowest overall values were observed in black beans. Two current commercial cultivars, Shania and Zorro, had low scores (1.8 to 2.6), whereas the older cultivars (Sutton and Coyne, 2002) had values greater than 4.0. A similar range from 1.8 to 4.4 was observed in the GN class but a smaller range in wilting was observed among pinto, pink, and small red genotypes (Tables 7 and 8). The Durango and Jalisco genotypes included both traditional type III cultivars bred under irrigation in the western United States and contemporary type II cultivars bred under rainfed conditions in the midwestern United States. Unifoliate senescence showed a similar range across all races with more striking differences in races Durango and Jalisco. This trait had an unacceptable high variability $(\mathrm{CV}=72 \%)$. The largest contrasts in stem greenness were observed in races of Mesoamerican genotypes, but stem pigmentation may have played a confounding role in these given the contrasting seed color types between black and navy beans (Table 6). Stem greenness ranged from 2.4 to 4.2 in the Durango race and from 2.0 to 3.4 in the Jalisco race where stem pigmentation associated with seedcoat color may have influenced the ratings. Recovery ratings illustrated the ability of some lines to recover from early severe stress, whereas others completely succumbed to the stress. Those genotypes with values of 1.0 are of interest because they might have a mechanism to help sustain them through a period of severe drought. A number of well-recognized sources of drought tolerance scored very poorly in this category [i.e., B98311 (0.5), SEA $10(0.0)$, and 'Common Red Mexican' (0.0)], suggesting that the drought tolerance

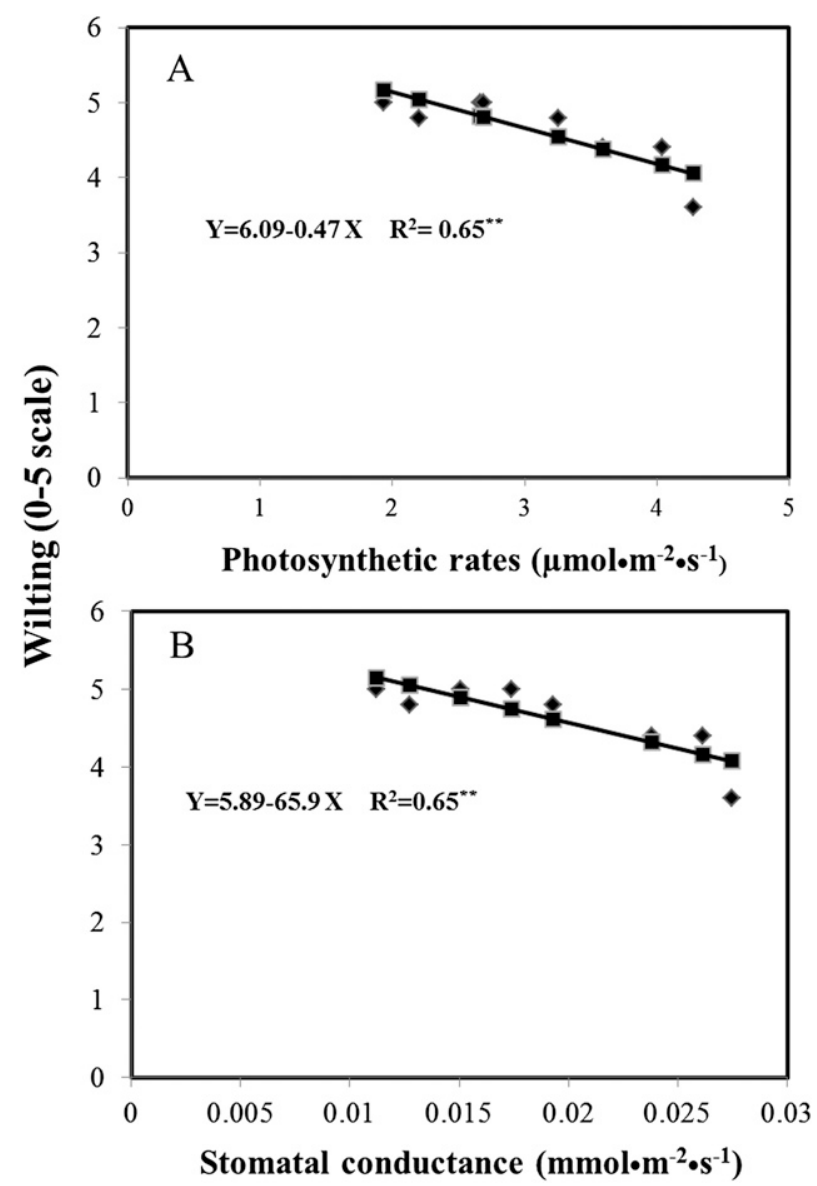

Fig. 1. Relationship between wilting and (A) photosynthesis and (B) stomatal conductance $\left(g_{\mathrm{S}}\right)$ for 10 common bean genotypes grown under drought stress conditions in the greenhouse. Wilting was scored at $18 \mathrm{~d}$ after planting on a scale of 0 to $5(0=$ no sign of wilting, $5=$ completely wilted $)$. Stomatal conductance and photosynthetic rates were measured at $18 \mathrm{~d}$ after planting. Square symbols are predicted values based on the regression model and the diamonds are the observed values. Each point represents an average of four experiments, each with five plants for each genotype.

observed in the field is largely dependent on the root system of these genotypes.

\section{Discussion}

Different wilting behaviors among the 10 common bean genotypes were observed during the progression of wilting under greenhouse conditions. 'Phantom' and 'Jaguar' maintained lower wilting scores compared with other genotypes, whereas 'Concepción', B98311, and L88-63 had higher wilting values at all observation dates. Wilting response of 'Jaguar', 'Phantom', and TARS-SR05 increased at a slower rate over time compared with other genotypes (data not shown). Interestingly, TARSSR05 was selected based on performance under conditions of compacted and water-logged soils infected with root rot causing fungi (Smith et al., 2007). At the end of experiments, those genotypes that wilted slowly were able to conserve water in leaves and stem tissues, survive the dry period, resume growth, and reproduce as evidenced by lower reduction of biomass and pod number (Tables 3 and 4). However, genotypes that wilted fast had relatively lower recovery rates and fewer pod numbers (Tables 1, 3, and 4) and a similar trend was observed among the 


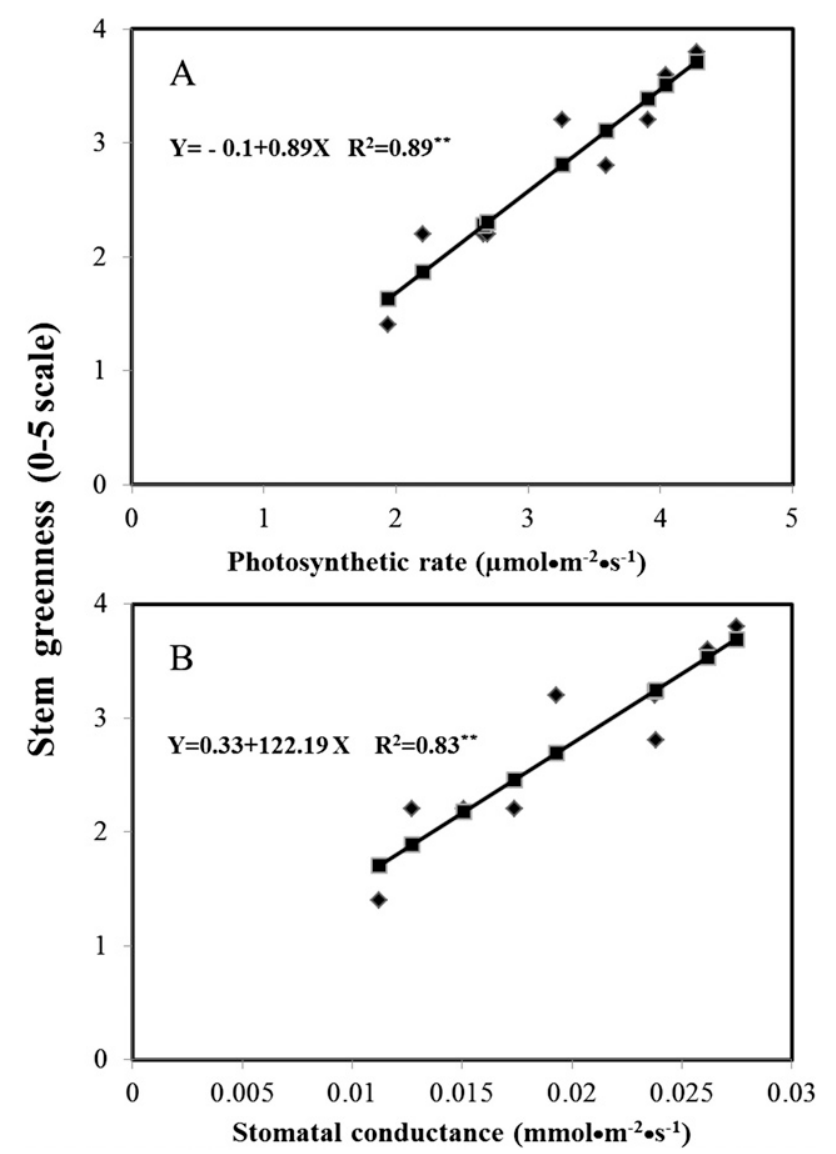

Fig. 2. Relationship between stem greenness and (A) photosynthesis and (B) stomatal conductance $\left(g_{\mathrm{S}}\right)$ recorded for 10 common bean genotypes grown under drought stress conditions in the greenhouse. Greenness was scored at $18 \mathrm{~d}$ after planting on a scale of 0 to $5(0=$ yellow stem, $5=$ completely green stem). Stomatal conductance and photosynthetic rates were measured at $18 \mathrm{~d}$ after planting. Square symbols are predicted values based on the regression model and the diamonds are the observed values. Each point represents an average of four experiments, each with five plants for each genotype.

96 BeanCAP entries. Black bean genotypes 'Eclipse', 'Shania', 'Zorro', and 'Avalanche' navy had low wilting scores and all had high recovery values (Table 6). Likewise in GN class 'Gemini' with a low wilting score had a recovery of 1.0 compared with 'Beryl' with a zero recovery and high wilting score of 4.4 (Table 7). In contrast, a few genotypes such as 'Matterhorn' GN and 'Kodiak' pinto showed high wilting scores but high recovery rates (Table 7). Interestingly, 'Matterhorn' has been recognized to possess moderate levels of drought resistance (Singh, 2007; Urrea et al., 2009). Among cultivars from the Jalisco race, Sedona and Merlot had intermediate wilting scores and high recovery rates (Table 8). Those genotypes with lower wilting scores may have a mechanism to slow their transpiration rate and not deplete their soil moisture reserves as quickly as genotypes that have a high wilting score as was observed in soybean (Ries et al., 2012). Because the slow wilting trait in these experiments was not associated with deep-water extraction because all genotypes were planted in shallow soil profiles, it is inferred that this trait is associated with mechanisms in the shoot.

In soybeans, slow wilting has been identified as a beneficial trait under drought. This condition involves a restricted transpiration rate under increasing vapor pressure deficit levels (Fletcher et al., 2007; Sadok et al., 2012). This phenotype was

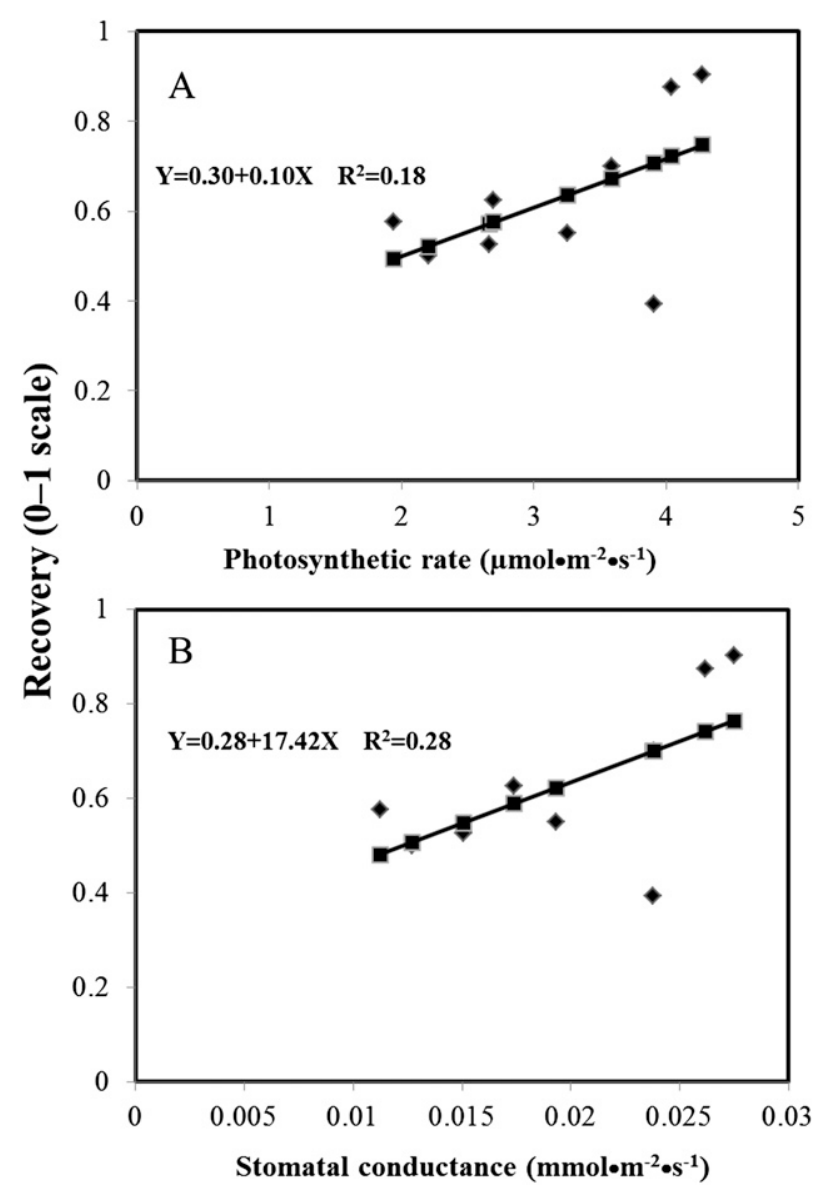

Fig. 3. Relationship between recovery and (A) photosynthesis and (B) stomatal conductance $\left(g_{\mathrm{S}}\right)$ recorded for 10 common bean genotypes grown under drought stress conditions in the greenhouse. Recovery was scored on a scale of 0 to $1(0=$ genotypes that did not recover, $0.5=$ genotypes with recovery from basal nodes, $1=$ genotypes that recovered from top meristems). Stomatal conductance and photosynthetic rates were measured at $18 \mathrm{~d}$ after planting, whereas the recovery was recorded 2 weeks after resuming watering. Square symbols are predicted values based on the regression model and the diamonds are the observed values. Each point represents an average of four experiments, each with five plants for each genotype.

initially identified in soybean PIs (PI471938 and PI416937) (Hufstetler et al., 2007; King et al., 2009; Sloane et al., 1990). The basis for this trait is attributed to limited hydraulic conductance between the leaf xylem and the guard cells (Sinclair et al., 2008). Furthermore, studies using aquaporin inhibitors have demonstrated their involvement in this trait (Sadok and Sinclair, 2010a, 2010b). Wilting is a trait expressed by plants that have passed the leaf water potential at turgor loss point. Leaf turgor loss point has been used to quantify plant drought tolerance levels (Bartlett et al., 2012), whereas visual assessment of wilting is commonly used as a measure of leaf water potential and seedling drought survival in trees (Engelbrecht et al., 2007). Plants that wilt slowly tend to maintain $g_{S}$, hydraulic conductance, photosynthesis, and growth at lower soil water potentials, which is especially important when drought occurs early during the growing season (Bartlett et al., 2012). Despite the absence of genotypic differences for photosynthetic rate and $g_{S}$ under stress conditions, 'Jaguar', TARS-SR05, and 'Phantom' had relatively higher values for these two parameters under stress and relatively lower values under non-stress conditions compared with the 
Table 6. Mean scores for wilting, unifoliate senescence, stem greenness after $21 \mathrm{~d}$ without water, and recovery of 28 Mesoamerican genotypes with specific scores for 15 representative genotypes evaluated under drought stress at the seedling stage. ${ }^{\mathrm{z}}$

\begin{tabular}{|c|c|c|c|c|c|c|}
\hline Genotype & Seed type & Growth habit ${ }^{\mathrm{y}}$ & $\begin{array}{c}\text { Wilting } \\
(0 \text { to } 5 \text { scale })^{\mathrm{x}}\end{array}$ & $\begin{array}{l}\text { Unifoliate senescence } \\
\quad(0 \text { to } 2 \text { scale })^{\mathrm{w}}\end{array}$ & $\begin{array}{l}\text { Stem greenness } \\
(0 \text { to } 5 \text { scale })^{\mathrm{v}}\end{array}$ & $\begin{array}{c}\text { Recovery } \\
(0 \text { to } 1 \text { scale })^{u}\end{array}$ \\
\hline B98311 & Black & II & 3.4 & 1.0 & 2.3 & 0.5 \\
\hline Domino & Black & II & 4.4 & 0.8 & 2.4 & 0.6 \\
\hline Eclipse & Black & II & 1.6 & 0.0 & 3.4 & 1.0 \\
\hline Jaguar & Black & II & 3.4 & 0.4 & 3.0 & 0.8 \\
\hline Midnight & Black & II & 4.2 & 1.6 & 1.8 & 0.2 \\
\hline Raven & Black & II & 4.6 & 0.4 & 2.0 & 0.9 \\
\hline Shania & Black & II & 1.8 & 0.0 & 3.0 & 1.0 \\
\hline Zorro & Black & II & 2.6 & 0.0 & 2.8 & 1.0 \\
\hline Fuji & Otebo & I & 3.7 & 0.9 & 3.6 & 0.7 \\
\hline Avalanche & Navy & II & 2.2 & 0.0 & 3.8 & 1.0 \\
\hline $\mathrm{C}-20$ & Navy & II & 4.0 & 0.8 & 4.0 & 0.8 \\
\hline Medalist & Navy & II & 4.2 & 1.2 & 3.6 & 0.6 \\
\hline Seafarer & Navy & I & 3.6 & 0.4 & 4.6 & 0.8 \\
\hline BAT 477 & Tan & III & 3.5 & 1.6 & 3.1 & 0.3 \\
\hline SEA 10 & Tan & III & 4.2 & 2.0 & 4.0 & 0.0 \\
\hline Mean $^{t}$ & & & 3.5 & 0.9 & 3.1 & 0.6 \\
\hline $\operatorname{LSD}_{0.05}{ }^{\mathrm{t}}$ & & & 1.2 & 0.8 & 0.9 & 0.4 \\
\hline$C V(\%)^{t}$ & & & 26 & 72 & 24 & 55 \\
\hline
\end{tabular}

${ }^{\mathrm{z} E a c h}$ point represents an average of four experiments, each with five plants for each genotype.

${ }^{y}$ Growth habit types II and III described by Singh (1982).

${ }^{\mathrm{x}} 0=$ no sign of wilting, $5=$ completely wilted.

"Number of senesced leaves (zero to two) when the most rapidly senescing genotype had dried unifoliates.

${ }^{\mathrm{v}} 0=$ yellow, $5=$ totally green.

${ }^{\mathrm{u}} 0=$ no recovery, $0.5=$ recovery from the basal meristem, $1=$ recovery from the apical meristem.

${ }^{t}$ Values derived from all 28 genotypes evaluated.

LSD $=$ least significant difference.

other genotypes. These results suggest that these genotypes might have saved water, which later allowed them to maintain photosynthesis under more severe water deficits. In other grain legumes such as soybean, peanut (Arachis hypogaea), chickpea (Cicer arietinum), and cowpea, maintaining maximum transpiration rates under relatively lower vapor pressure deficits has been recognized as a soil water-saving strategy in tolerant genotypes (Belko et al., 2012; Devi et al., 2010; Sinclair et al., 2008; Zaman-Allah et al., 2011). In contrast, an early study of common bean showed that all cultivars under study reached the maximum transpiration at similar values of leaf to air humidity gradient despite genotypic differences in $g_{\mathrm{S}}$ (Comstock and Ehleringer, 1993). In that study, different genotypes were grown in 1-m-long polyvinylchloride tubes with a large volume of soil and watered every $3 \mathrm{~d}$ as opposed to the severe drought treatment of the current study, which limits a direct comparison of the two studies. Because genotypes with low wilting rates were able to maintain relatively high $g_{\mathrm{S}}$ and photosynthesis, it would be interesting to study the transpiration behavior of common bean in relation to vapor pressure deficit and determine if common bean genotypes behave in a similar fashion to their related legume species.

Unifoliate senescence was positively correlated to wilting $[r=0.62 * * *(P \leq 0.001)]$ but negatively correlated to stem greenness, recovery as well as the productivity parameters of pod number and biomass. Although it is possible to distinguish genotypes based on the progression of the senescing unifoliates in cowpea (Muchero et al., 2008), there were no notable differences in this trait among common bean genotypes. Bean unifoliates stayed green until their complete desiccation, which eliminated the confusion among drought, aging, and nutrient deficiency. Selection based on this trait is unlikely to be useful based on the very high level of variability $(\mathrm{CV}=72 \%)$ observed among the BeanCAP genotypes.

Stem greenness was positively correlated with recovery $(r=$ $\left.0.65^{* * *}\right)$. Stepwise regression analysis to determine which shoot variables could be used to predict recovery from drought showed that stem greenness and wilting contributed significantly to the regression model. These two variables combined explained $48 \%$ of the variation in recovery. Stem greenness alone accounted for $43 \%$, whereas wilting accounted for only $5 \%$ of the variation in recovery. Additionally, $g_{\mathrm{S}}$ and photosynthetic rate regression to wilting, stem greenness, and recovery showed that these two variables explained more stem greenness $\left(R^{2}=0.83^{* * *}\right.$ and $\left.R^{2}=0.89^{* * *}\right)$ variability than wilting $\left(R^{2}=\right.$ $\left.0.65^{* * *}\right)$ and recovery $\left(R^{2}=0.58^{*}\right.$ and $\left.R^{2}=0.53^{*}\right)$. These results suggest that bean genotypes need to maintain a viable green stem to be able to recover from drought and resume growth. However, 'Fuji' was an exception to this trend because it usually maintained a green stem. At the resumption of irrigation, instead of recovering, 'Fuji' seedlings continued to dry-down from the top and subsequently died. These results suggest that when exposed to a severe drought in the seedling stage, seedlings of 'Fuji' were unable to recover from drought stress relief, probably because of its determinate growth habit. Under severe drought stress of 2010 in the field in Michigan, 'Fuji' showed a growth pattern of producing excessive vegetative tissue instead of setting flowers and pods because small pods aborted as a result of stress. The confounding effect of stem pigmentation on the rating of stem greenness in color-contrasting seed types may limit its usefulness 
Table 7. Mean scores for wilting, unifoliate senescence, stem greenness after $21 \mathrm{~d}$ without water, and recovery of 50 Durango common bean genotypes with specific scores for 19 representative genotypes evaluated under drought stress at the seedling stage. ${ }^{\mathrm{z}}$

\begin{tabular}{|c|c|c|c|c|c|c|}
\hline Genotype & Seed type ${ }^{\mathrm{y}}$ & Growth habit ${ }^{\mathrm{x}}$ & $\begin{array}{c}\text { Wilting } \\
(0 \text { to } 5 \text { scale })^{\mathrm{w}}\end{array}$ & $\begin{array}{l}\text { Unifoliate senescence } \\
(0 \text { to } 2 \text { scale })^{\mathrm{v}}\end{array}$ & $\begin{array}{c}\text { Stem greenness } \\
(0.5 \text { scale })^{\mathrm{u}}\end{array}$ & $\begin{array}{c}\text { Recovery } \\
(0 \text { to } 1 \text { scale })^{t}\end{array}$ \\
\hline Beryl R & GN & III & 4.4 & 2.0 & 4.0 & 0.0 \\
\hline Gemini & GN & III & 1.8 & 0.0 & 4.2 & 1.0 \\
\hline GN9-1 & GN & III & 4.6 & 2.0 & 3.4 & 0.0 \\
\hline Marquis & GN & III & 4.8 & 2.0 & 3.8 & 0.0 \\
\hline Matterhorn & GN & II & 4.4 & 0.0 & 4.0 & 1.0 \\
\hline Weihing & GN & II & 4.4 & 1.2 & 3.8 & 0.4 \\
\hline Bill Z & Pinto & III & 3.6 & 2.0 & 3.0 & 0.0 \\
\hline Common Pinto & Pinto & III & 3.8 & 0.4 & 2.4 & 1.0 \\
\hline Croissant & Pinto & II & 3.8 & 2.0 & 2.4 & 0.0 \\
\hline Fisher & Pinto & III & 4.0 & 0.0 & 2.4 & 1.0 \\
\hline Kodiak & Pinto & II & 4.0 & 0.0 & 4.2 & 1.0 \\
\hline $\mathrm{La} \mathrm{Paz}$ & Pinto & II & 2.4 & 0.0 & 3.4 & 1.0 \\
\hline Lariat & Pinto & II & 3.6 & 1.6 & 3.0 & 0.4 \\
\hline Montrose & Pinto & III & 3.8 & 2.0 & 3.0 & 0.0 \\
\hline Othello & Pinto & III & 3.6 & 1.4 & 2.2 & 0.7 \\
\hline San Juan & Pinto & III & 2.6 & 0.0 & 3.8 & 1.0 \\
\hline Santa Fe & Pinto & II & 2.4 & 0.4 & 3.6 & 0.8 \\
\hline Sierra & Pinto & II & 4.8 & 0.4 & 4.0 & 0.8 \\
\hline Stampede & Pinto & II & 4.4 & 2.0 & 3.0 & 0.1 \\
\hline Mean $^{\mathrm{s}}$ & & & 3.5 & 1.0 & 3.3 & 0.6 \\
\hline $\operatorname{LSD}_{0.05}{ }^{\mathrm{s}}$ & & & 1.2 & 0.8 & 0.9 & 0.4 \\
\hline $\mathrm{CV}(\%)^{\mathrm{s}}$ & & & 26 & 72 & 24 & 55 \\
\hline
\end{tabular}

${ }^{\mathrm{z}}$ Each point represents an average of four experiments, each with five plants for each genotype.

${ }^{\mathrm{y}} \mathrm{GN}=$ Great Northern.

${ }^{\mathrm{x}}$ Growth habit types II and III described by Singh (1982).

${ }^{\mathrm{w}} 0=$ no sign of wilting, $5=$ completely wilted.

${ }^{\mathrm{N}}$ Number of senesced leaves (zero to two) when the most rapidly senescing genotype had dried unifoliates.

${ }^{\mathrm{u}} 0=$ yellow, $5=$ totally green .

${ }^{\mathrm{t}} 0=$ no recovery, $0.5=$ recovery from the basal meristem, 1 recovery from the apical meristem.

${ }^{\mathrm{s}}$ Values derived from all 50 genotypes evaluated.

as a selectable characteristic across a broad range of bean genotypes.

Drought-tolerant genotypes B98311 and L88-63 not only had lower stem greenness and recovery rates, but also performed poorly in general in all experiments (Table 1). B98311 is a parent of L88-63 and X00822 one of the parents of 'Zorro'. B98311 and L88-63 were selected based on root length under terminal drought (Frahm et al., 2004; Henry et al., 2010) and 'Zorro' performs relatively well under field drought stress. The fact that B98311 and L88-63 behaved poorly and similarly in constrained root growth conditions highlights the complexity associated with breeding for drought tolerance and strengthens the importance of knowing the target environment as well as the growth stage at which the crop is likely to encounter drought. Other genotypes such as SEA 10 and BAT 477 known as a source of drought tolerance in the field (Beebe et al., 2013) performed very poorly in these tests. Because root growth was restricted, drought tolerance in these genotypes may reside in root characteristics that were not expressed in this study. In addition, these results highlight the importance of combining root and shoot drought traits to achieve stability in drought tolerance over a range of soil conditions. The general prediction of the recovery based on high wilting scores and stem greenness in different genotypes suggests that these criteria can be used as a screening proxy for drought tolerance expressed at early stages of shoot development in common bean. An interesting trend emerged in that those genotypes such as UI-239, UI-537, 'Montrose', and 'Bill $Z$ ' developed under irrigation in the semiarid western United States tended to have lower recovery ratings than genotypes such as 'Matterhorn', 'Sedona', and 'Merlot' developed in programs located in the rainfed midwestern United States. The major exception was the two pinto genotypes 'San Juan' and 'Fischer' that were developed in southwestern Colorado for dryland production. They showed high recovery rates as compared with 'Croissant' pinto developed under irrigation for production in the rain shadow on the eastern slope of the Rocky Mountains.

Interestingly, stem greenness was identified to be an important seedling trait associated with drought tolerance in cowpea, which is the closest relative of common bean (Muchero et al., 2008). Cowpea is recognized as the most drought-tolerant legume species (Hall, 2012), whereas common bean is among the least tolerant. Sharing the same trait for drought tolerance at the pod number and seedling stage suggests that this trait might be under the same genetic control in these two legume species. Common bean is generally grown in wetter environments than cowpea and rarely experiences drought conditions affecting stem greenness that occur during the bean growth season. Because wilting was negatively correlated to stem greenness and recovery $\left(r=-0.82^{* * *}\right.$ and $\left.-0.81^{* * *}\right)$, respectively, wilting might be a more practical trait to measure than stem greenness in common bean. For drought tolerance screening purposes, combining delayed wilting and stem greenness would provide more 
Table 8. Mean scores for wilting, unifoliate senescence, stem greenness after $21 \mathrm{~d}$ without water, and recovery of 18 Jalisco common bean genotypes with specific scores for ten representative genotypes evaluated under drought stress at the seedling stage. ${ }^{\mathrm{z}}$

\begin{tabular}{|c|c|c|c|c|c|c|}
\hline Genotype & Seed type & Growth habit ${ }^{\mathrm{y}}$ & $\begin{array}{c}\text { Wilting } \\
(0 \text { to } 5 \text { scale })^{\mathrm{x}}\end{array}$ & $\begin{array}{l}\text { Unifoliate senescence } \\
\quad(0 \text { to } 2 \text { scale })^{\mathrm{w}}\end{array}$ & $\begin{array}{l}\text { Stem greenness } \\
(0 \text { to } 5 \text { scale })^{\mathrm{v}}\end{array}$ & $\begin{array}{c}\text { Recovery } \\
(0 \text { to } 1 \text { scale })^{u}\end{array}$ \\
\hline Gloria & Pink & III & 3.6 & 2.0 & 3.4 & 0.0 \\
\hline ROG 312 & Pink & III & 4.8 & 1.6 & 2.0 & 0.3 \\
\hline Roza & Pink & III & 3.6 & 0.6 & 2.8 & 1.0 \\
\hline Sedona & Pink & II & 2.8 & 0.0 & 3.4 & 1.0 \\
\hline UI-537 & Pink & III & 4.6 & 2.0 & 2.4 & 0.0 \\
\hline Victor & Pink & III & 2.6 & 0.2 & 2.4 & 0.8 \\
\hline Common Red Mexican & Small red & III & 4.4 & 2.0 & 2.2 & 0.0 \\
\hline Merlot & Small red & II & 3.0 & 0.0 & 3.2 & 1.0 \\
\hline UI-239 & Small red & III & 4.4 & 2.0 & 2.6 & 0.0 \\
\hline USRM-20 & Small red & III & 3.8 & 0.2 & 3.4 & 0.8 \\
\hline Mean $^{t}$ & & & 3.7 & 1.2 & 2.7 & 0.5 \\
\hline $\operatorname{LSD}_{0.05}{ }^{\mathrm{t}}$ & & & 1.2 & 0.8 & 0.9 & 0.4 \\
\hline$C V(\%)^{t}$ & & & 26 & 72 & 24 & 55 \\
\hline
\end{tabular}

${ }^{\mathrm{z}}$ Each point represents an average of four experiments, each with five plants for each genotype.

${ }^{\mathrm{y}}$ Growth habit types II and III described by Singh (1982).

${ }^{\mathrm{x}} 0=$ no sign of wilting, $5=$ completely wilted.

"Number of senesced leaves (zero to two) when the most rapidly senescing genotype had dried unifoliates.

${ }^{\mathrm{v}} 0=$ yellow, $5=$ totally green.

${ }^{\mathrm{u}} 0=$ no recovery, $0.5=$ recovery from the basal meristem, $1=$ recovery the apical meristem.

${ }^{t}$ Values derived from all 18 genotypes evaluated.

useful information about genotypic differences in terms of drought tolerance. Determining the usefulness of these two traits as predictors of drought tolerance in the field will be difficult because root traits play a major confounding role in all field studies. Biomass was significantly reduced by drought. These results suggest that severe drought in the seedling stage might have deleterious effects on yield through reduced biomass accumulation. This is important because the plants may not have sufficient time to invest in biomass production after an extended period of drought. Instead they might directly enter the reproductive period without sufficient biomass reserves for optimum yield. This could be disadvantageous for common bean genotypes with a determinate growth habit, which may not be able to initiate a second flush of pod setting when the vegetative growth period has passed.

\section{Conclusions}

Screening protocols in controlled environments are needed to select drought-tolerant bean cultivars. These screening methods need to be fast and effective to be integrated into breeding programs. Seedling drought tolerance screening methods would allow for the screening of numerous lines in a relatively short period at low cost when compared with field trials under contrasting water treatments commonly used to compare yields. This study was conducted to determine shoot traits that are associated with drought tolerance at an early development stage in common bean. The study was conducted in the greenhouse using small pots and a limited amount of soil to constraint root growth. Four shoot traits, wilting, unifoliate senescence, stem greenness, and recovery from drought, were evaluated in a wide range of common bean genotypes. Stomatal conductance and photosynthetic rate were measured to understand the cause of change in these traits in a control group. In addition, the number of pods and the biomass were evaluated to quantify the impact of seedling-stage drought stress on plant productivity. Plant growth and productivity after drought stress are dependent on the degree of recovery from stress. Wilting was negatively correlated with recovery, whereas stem greenness was highly positively correlated with recovery. Those genotypes with high recovery values that differ in wilting response could be combined because contrasting mechanisms for drought tolerance may reside in these genotypes. Certain common bean genotypes, known to have drought tolerance conferred by deep rooting capacity, performed poorly in the shallow soil profiles used in these experiments. Having an assay that allows for a separation of root and shoot traits functional in drought tolerance in common bean would provide breeders with a means to combine these mechanisms into a single cultivar that could enhance performance under a broad range of soil moisture conditions.

\section{Literature Cited}

Bartlett, M.K., C. Scoffoni, and L. Sack. 2012. The determinants of leaf turgor loss point and prediction of drought tolerance of species and biomes: A global meta-analysis. Ecol. Lett. 15:393-405.

Beebe, S.E. 2012. Common bean breeding in the tropics. Plant Breed. Rev. 36:357-426.

Beebe, S.E., I.M. Rao, M.W. Blair, and J.A. Acosta-Gallegos. 2013. Phenotyping common beans for adaptation to drought. Frontiers Physiol. 4:1-20.

Belko, N., M. Zaman-Allah, N. Cisse, N.N. Diop, G. Zombre, J.D. Ehlers, and V. Vadez. 2012. Lower soil moisture threshold for transpiration decline under water deficit correlates with lower canopy conductance and higher transpiration efficiency in drought-tolerant cowpea. Funct. Plant Biol. 39:306-322.

Blum, A. 1996. Crop responses to drought and the interpretation of adaptation. Plant Growth Regulat. 20:135-148.

Castrillo, M., D. Fernandez, A.M. Calcagno, I. Trujillo, and L. Guenni. 2001. Response of ribulose-1, 5-bisphosphate carboxylase, protein content, and stomatal conductance to water deficit in maize, tomato, and bean. Photosynthetica 39:221-226.

Chaves, M.M., J.M. Costa, and N.J.M. Saibo. 2011. Recent advances in photosynthesis under drought and salinity. Adv. Bot. Res. 57:50-104. 
Common Bean Coordinated Agricultural Project. 2011. Dry bean genotypes BeanCAP. 26 July 2013. <http://www.beancap.org/_pdf/ Beancap_Field_trials.pdf $>$.

Comstock, J. and J. Ehleringer. 1993. Stomata1 response to humidity in common bean (Phaseolus vulgaris): Implications for maximum transpiration rate, water-use efficiency and productivity. Austral. J. Plant Physiol. 20:669-691.

DeDatta, S.K., J.A. Malabuyoc, and E.L. Aragon. 1988. A field screening technique for evaluating rice germplasm for drought tolerance during the vegetative stage. Field Crops Res. 19:123-134. Desclaux, D., T. Huynh, and P. Roumet. 2000. Identification of soybean plant characteristics that indicate the timing of drought stress. Crop Sci. 40:716-722.

Devi, M.J., T.R. Sinclair, and V. Vadez. 2010. Genotypic variation in peanut for transpiration response to vapor pressure deficit. Crop Sci. 50:191-196.

Dias, M.C. and W. Brüggemann. 2010. Limitations of photosynthesis in Phaseolus vulgaris under drought stress: Gas exchange, chlorophyll fluorescence and Calvin cycle enzymes. Photosynthetica 48:96-102.

Engelbrecht, B.M., M.T. Tyree, and T.A. Kursar. 2007. Visual assessment of wilting as a measure of leaf water potential and seedling drought survival. J. Trop. Ecol. 23:497-500.

Fletcher, A.L., T.R. Sinclair, and L.H. Allen, Jr. 2007. Transpiration responses to vapour pressure deficit in well watered 'slow-wilting' and commercial soybean. Environ. Exp. Bot. 61:145-151.

Frahm, M.A., J.C. Rosas, N. Mayek-Perez, E. Lopez-Salinas, J.A. Acosta-Gallegos, and J.D. Kelly. 2004. Breeding beans for tolerance to terminal drought in the lowland tropics. Euphytica 136:223-232.

Ghaderi, A., J.D. Kelly, M.W. Adams, A.W. Saettler, G.L. Hosfield, G.V. Varner, M.A. Uebersax, and J. Taylor. 1990. Registration of 'Blackhawk' tropical black bean. Crop Sci. 30:744-745.

Hall, A.E. 2012. Phenotyping cowpeas for adaptation to drought. Frontiers Physiol. 3:2-8.

Henry, A., J.C. Rosas, J.S. Beaver, and J.P. Lynch. 2010. Multiple stress response and belowground competition in multilines of common bean (Phaseolus vulgaris L.). Field Crops Res. 117:209-218.

Hufstetler, E.V., H.R. Boerma, T.E. Carter, and H.G. Earl. 2007. Genotypic variation for three physiological traits affecting drought tolerance in soybean. Crop Sci. 47:25-35.

Kamoshita, A., R.C. Babu, N.M. Boopathi, and S. Fukai. 2008. Phenotypic and genotypic analysis of drought-resistance traits for development of rice cultivars adapted to rainfed environments. Field Crops Res. 109:1-23.

Kelly, J.D., G.L. Hosfield, G.V. Varner, M.A. Uebersax, and J. Taylor. 2000. Registration of Phantom black bean. Crop Sci. 40:572.

Kelly, J.D., G.L. Hosfield, G.V. Varner, M.A. Uebersax, and J. Taylor. 2001. Registration of Jaguar black bean. Crop Sci. 41:1647.

Kelly, J.D., G.V. Varner, P. O’Boyle, and B. Long. 2009a. Registration of 'Zorro' black bean. J. Plant Registrations 3:226-230.

Kelly, J.D., G.V. Varner, B. Román, and B. Long. 2009b. Registration of 'Fuji' otebo bean. J. Plant Registrations 3:223-225.

King, C.A., L.C. Purcell, and K.R. Brye. 2009. Differential wilting among soybean genotypes in response to water deficit. Crop Sci. 49:290-298.

Littell, R.C., G.A. Milliken, W.W. Stroup, R.D. Wolfinger, and O. Schabenberger. 2006. SAS for mixed models. 2nd Ed. SAS Institute, Cary, NC.

Lizana, C., M. Wentworth, J.P. Martinez, D. Villegas, R. Meneses, E.H. Murchie, C. Pastenes, B. Lercari, P. Vernieri, P. Horton, and M. Pinto. 2006. Differential adaptation of two varieties of common bean to abiotic stress: I. Effects of drought on yield and photosynthesis. J. Expt. Bot. 57:685-697.

Longenberger, P.S., C.W. Smith, P.S. Thaxton, and B.L. McMichael. 2006. Development of a screening method for drought tolerance in cotton seedlings. Crop Sci. 46:2104-2110.

Mitchell, J.H., D. Siamhan, M.H. Wamala, J.B. Risimeri, E. Chinyamakobvu, S.A. Henderson, and S. Fukai. 1998. The use of seedling leaf death score for evaluation of drought resistance of rice. Field Crops Res. 55:1-2.

Muchero, W., J.D. Ehlers, and P.A. Roberts. 2008. Seedling stage drought induced phenotypes and drought responsive genes in diverse cowpea genotypes. Crop Sci. 48:541-552.

Ninou, E., J.T. Tsialtas, C.A. Dordas, and D.K. Papakosta. 2013. Effect of irrigation on the relationships between leaf gas exchange related traits and yield in dwarf dry bean grown under Mediterranean conditions. Agr. Water Mgt. 116:235-241.

Rauf, S. 2008. Breeding sunflower (Helianthus annuus L.) for drought tolerance. Commun. Biometry Crop Sci. 3:29-44.

Ries, L.L., L.C. Purcell, T.E. Carter, J.T. Edwards, and C.A. King. 2012. Physiological traits contributing to differential canopy wilting in soybean under drought. Crop Sci. 52:272-281.

Sadok, W., M.E. Gilbert, M. Aown, S. Raza, and T.R. Sinclair. 2012. Basis of slow wilting phenotype in soybean PI 471938. Crop Sci. 52:1261-1269.

Sadok, W. and T.R. Sinclair. 2010a. Genetic variability of transpiration response of soybean [Glycine $\max$ (L.) Merr.] shoots to leaf hydraulic conductance inhibitor $\mathrm{AgNO}_{3}$. Crop Sci. 50:1423-1430.

Sadok, W. and T.R. Sinclair. 2010b. Transpiration response of 'slowwilting' and commercial soybean [Glycine $\max (\mathrm{L}$.) Merr.] genotypes to three aquaporin inhibitors. J. Expt. Bot. 61:821-829.

Sinclair, T.R., M.A. Zwieniecki, and N.M. Holbrook. 2008. Low leaf hydraulic conductance associated with drought tolerance in soybean. Physiol. Plant. 132:446-451.

Singh, B.B., Y. Mai-Kodomi, and T. Terao. 1999. A simple screening method for drought tolerance in cowpea. Indian J. Genet. 59:211220.

Singh, S.P. 1982. A key for identification of different growth habits of Phaseolus vulgaris L. Annu. Rpt. Bean Improv. Coop. 25:92-95.

Singh, S.P. 2007. Drought resistance in the race Durango dry bean landraces and cultivars. Agron. J. 99:1219-1225.

Singh, S.P., P. Gepts, and D.G. Debouck. 1991. Races of common bean (Phaseolus vulgaris, Fabaceae). Econ. Bot. 45:379-396.

Sloane, R.J., R.P. Patterson, and T.E. Carter. 1990. Field drought tolerance of a soybean plant introduction. Crop Sci. 30:118-123.

Smith, J.R., S.J. Park, J.S. Beaver, P.N. Miklas, C.H. Canaday, and M. Zapata. 2007. Registration of TARS-SR05 multiple disease-resistant dry bean germplasm. Crop Sci. 47:457-458.

Sutton, L.A. and D.P. Coyne. 2002. Bean-Dry. In: T.C. Wehner (ed.). Vegetable cultivar descriptions for North America. List 26. HortScience 37:16-18.

Tomar, S.M.S. and G.T. Kumar. 2004. Seedling survivability as a selection criterion for drought tolerance in wheat. Plant Breed. 123:392-394.

Urrea, C.A., C.D. Yonts, D.J. Lyon, and A.E. Koehler. 2009. Selection for drought tolerance in dry bean derived from the Mesoamerican gene pool in western Nebraska. Crop Sci. 49:2005-2010.

Watanabe, S., S. Hakoyama, T. Terao, and B.B. Singh. 1997. Evaluation methods for drought tolerance of cowpea, p. 141-146. In: Singh, B.B., D.R. Mohan Raj, K.E. Dashiell, and L.E.N. Jackai (eds.). Advances in cowpea research. Intl. Inst. Trop. Agr., Ibadan, Nigeria.

Wentworth, M., E.H. Murchie, J.E. Gray, D. Villegas, C. Pastenes, M. Pinto, and P. Horton. 2006. Differential adaptation of two varieties of common bean to abiotic stress: II. Acclimation of photosynthesis. J. Expt. Bot. 57:699-709.

White, J.W. and J.A. Castillo. 1989. Relative effect of root and shoot genotypes on yield of common bean under drought stress. Crop Sci. 29:360-362.

Zaman-Allah, M., D.M. Jenkinson, and V. Vadez. 2011. A conservative pattern of water use, rather than deep or profuse rooting, is critical for the terminal drought tolerance of chickpea. J. Expt. Bot. 62:4239-4252.

Zhang, H., G. Gong, S. Guo, Y. Ren, and Y. Xu. 2011. Screening the USDA watermelon germplasm collection for drought tolerance at the seedling stage. HortScience 46:1245-1248. 